ENTREVISTA

\title{
PERSPECTIVAS PARA FORMAÇÃO DE PROFESSORES PÓS PANDEMIA: UM DIÁLOGO
}

\author{
PERSPECTIVES FOR THE TRAINING OF POST-PANDEMIC TEACHERS: A \\ DIALOGUE
}

\begin{abstract}
PERSPECTIVAS PARA LA FORMACIÓN DE PROFESORES POSPANDÉMICOS: UN DIÁLOGO
\end{abstract}

\author{
Bernardete Angelina Gatti \\ Fundação Carlos Chagas - Brasil
}

\author{
Gisele Soares Lemos Shaw \\ Universidade Federal do Vale do São Francisco - Brasil \\ Jocilene Gordiano Lima Tomaz Pereira \\ Universidade Federal do Vale do São Francisco - Brasil
}

\begin{abstract}
Resumo: Diante do cenário de isolamento social em decorrência de pandemia do COVID-19 buscouse propiciar diálogos com pesquisadores e professores brasileiros, da área de educação, buscando direcionamentos para educação formal no período. Assim, foi realizada entrevista com a professora Bernardete Angelina, Gatti, pesquisadora de referência no campo de formação de professores. Objetivou-se, nessa atividade, discutir a formação de professores no Brasil, diante do cenário da pandemia, apontando para as possíveis estratégias a serem adotadas por Instituições de Ensino Superior, no âmbito de cursos de formação docente, durante e após a pandemia. A entrevista ocorreu por meio de live, transmitida no site do Youtube, mediada por duas professoras universitárias e transcrita. Gatti discutiu sobre a atuação de estados e municípios frente aos desafios da educação durante o isolamento social, sobre possibilidades de ação das universidades, nesse cenário, avaliou a educação à distância e apontou esse momento como um caminho para repensar a formação de professores no país.
\end{abstract}

Palavras chave: Educação; Formação; Pandemia.

\begin{abstract}
Given the scenario of social isolation due to the COVID-19 pandemic, we sought to provide dialogues with Brazilian researchers and teachers in the area of education, seeking directions for formal education in the period. Thus, an interview was conducted with Professor Bernardete Angelina, Gatti, a reference researcher in the field of teacher education. The objective of this activity was to discuss teacher training in Brazil, in view of the pandemic scenario, pointing to the possible strategies to be adopted by Higher Education Institutions, within the scope of teacher training courses, during and after the pandemic. The interview took place via live, broadcast on the Youtube website, mediated by two university teachers and transcribed. Gatti discussed the role of states and municipalities in the face of education challenges during social isolation, about the possibilities of action by universities, in this scenario, he evaluated distance education and pointed out this moment as a way to rethink the training of teachers in the country.
\end{abstract}

Keywords: Education; Training; Pandemic. 
Resumen: Ante el escenario de aislamiento social derivado de la pandemia COVID-19, se intentó dialogar con investigadores y docentes brasileños en el área de educación, buscando orientaciones para la educación formal en el período. Así, se realizó una entrevista con el profesor Bernardete Angelina, Gatti, investigador que es un referente en el área de formación docente. El objetivo de esta actividad fue discutir la formación docente en Brasil, ante el escenario pandémico, señalando las posibles estrategias a ser adoptadas por las Instituciones de Educación Superior, en el ámbito de los cursos de formación docente, durante y después de la pandemia. La entrevista se realizó a través de transmisión en vivo en el sitio web de YouTube, mediada por dos profesores universitarios y transcrita. Gatti discutió el rol de los estados y municipios ante los desafíos de la educación durante el aislamiento social, sobre las posibilidades de acción de las universidades, en este escenario, evaluó la educación a distancia y señaló este momento como una forma de repensar la formación de docentes en el país.

Palabras clave: Educación; Capacitación; Pandemia.

\section{Introdução}

As comunicações interpessoais, via internet e ao vivo, realizadas em diferentes suportes e por variadas plataformas, reunindo grupos de pessoas geralmente em lugares distanciados, as chamadas Lives (viver / "ao vivo"), eclodiram no contexto das Instituições Educacionais Brasileiras no cenário de pandemia da Covid $19^{1}$, em que as orientações sanitárias apontavam para o isolamento social como essencial para o controle pandêmico. A possibilidade de "viver" a presença, sem estar fisicamente presente, de interagir virtual e simultaneamente, proporcionada pelas lives, rapidamente se tornou um procedimento educativo, como caminho didático alternativo de ensinar e aprender, ou seja, como um novo arranjo "espacial" da sala de aula. Sua utilização cresceu, também, na realização de eventos científicos com centenas ou milhares de participantes, mostrando-se um caminho viável para a continuidade das comunicações educacionais e científicas.

Este artigo tem por base a transcrição de uma Live, ocorrida no dia 21 de maio de 2020, com transmissão e interatividade simultâneas, por isso traz em sua textualidade o formato de diálogo, marcas de linguagem oral, algumas palavras onomatopaicas e fusão de expressões populares e cultas. Em algumas partes ajustes da oralidade à escrita foram realizados. Portanto, um texto híbrido e uma apresentação mais dialógica, ao mesmo tempo resguardando sua característica acadêmica.

\footnotetext{
${ }^{1}$ A pandemia COVID-19 que começou a grassar em 2020 é causada por corona vírus, SARS-CoV2. É uma doença que possui espectro clínico que pode ser sintomático ou assintomático, tem provocado milhões de mortes no mundo todo, é de rápida e fácil transmissão.
} 


\section{Abrindo o diálogo}

[PEREIRA, J.G.L.T.] Boa tarde a todos e todas! Sejam bem-vindos e bem-vindas a essa live que vai abordar as perspectivas para formação de professores pós-pandemia. A nossa convidada é a Professora Doutora Bernardete Angelina Gatti, uma das principais pesquisadoras na área educação, com destaque na formação de professores, desenvolvendo estudos e pesquisas junto à Fundação Carlos Chagas, membro titular da Academia Paulista de Educação e autora de várias obras que servem como referência para muitos profissionais de educação. Uma honra professora tê-la conosco, sinta-se acolhida. Contamos também com a participação da Professora Dra. Gisele Lemos Shaw, do Colegiado de Ciências da Natureza da UNIVASF, Campus Senhor do Bonfim, que tem como foco de pesquisa a formação de professores com ênfase no ensino de ciências e educação inclusiva. Obrigada professora pela sua presença! O objetivo desta Live é ser um espaço de interlocução, portanto, os que desejarem podem participar enviando questões, dúvidas, sobre o tema, que serão respondidas, na medida do possível, pela professora Bernardete. Antes de iniciar nossa discussão, registro nosso agradecimento ao tradutor e intérprete de Libras/Português Davi Lima, do Núcleo de Acessibilidade e Inclusão da Univasf, que fará a tradução simultânea para Língua Brasileira de Sinais, e também agradecer o apoio da TV Caatinga, da Pró-Reitoria de Ensino e da Secretaria de Educação a Distância da UNIVASF. Professora Bernardete, diante desse diferente cenário de pandemia, quais são os principais desafios que as universidades e os cursos de formação de professores estão enfrentando e que irão enfrentar?

[GATTI, B. A.] Bom, primeiro quero agradecer o convite de vocês, de poder compartilhar ideias. É uma alegria poder conversar, poder trocar e tocar nesse assunto num momento tão delicado como o que estamos vivendo. Não sei se vocês podem imaginar nossa situação aqui, na cidade de São Paulo, com 10 milhões de habitantes, num espaço pequenininho, né? Muitos contatos em qualquer lugar. Nós somos muito afetados com essa situação, ela nos toca e nos perturba. Mas, vamos à sua questão. Eu tenho estado em contato com gestores, coordenadores, com professores, com licenciandos, através de lives e através de minicursos e colóquios que o IEA/USP tem oferecido, e tenho percebido a angústia e a ansiedade de todo mundo. Realmente, a pergunta que está na cabeça de todos é: quando voltaremos às presenças, e, quando podemos voltar? Essa, a questão do retorno às atividades presenciais, é uma coisa que está na cabeça de todos. Isso porque, evidentemente, mesmo numa única instituição, você terá situações extremamente diferentes, porque mesmo com a tentativa de manter os cursos vivos - através de 
sistemas de educação aberta a distância - a gente verifica que nem todos os alunos têm acesso aos recursos necessários, há uma diversidade muito grande entre eles em sua condição social e econômica, e o retorno realmente é uma incógnita: como voltaremos? O que se aprendeu? Que vivências nos marcaram e aos alunos? Isso nos coloca um problema bastante sério: sobre como vamos desenvolver o currículo necessário para que esses licenciandos possam ter sua base de profissionalidade constituída e segurança para atuar com as crianças e jovens com quem eles irão trabalhar. Então, estamos aí, com um desafio às universidades - a consideração dos diferenciais de aprendizagem criados pelo distanciamento social e os diferentes contextos e condições do alunado, que desafiam a criação de possibilidades curriculares variadas e ambiências de aprendizagem para esses licenciandos, que devem ser consideradas. Isso põe para nós o desafio de que temos que nos preparar muito para esse retorno, porque caberá a nós um acolhimento sensível desses alunos, desses estudantes. Não é pensar assim, que eles vão voltar, fizeram tudo, se não fizeram é porque não fizeram, não é, não. Acho que todo mundo está procurando alternativas e nós temos alunos em condições muito diferentes, então, temos que ter, em primeiro lugar, uma grande sensibilidade para recebê-los de volta e analisar com eles as situações vividas e o que puderam apreender. Primeiro, que experiências viveram nesse período, então o que eles aprenderam no geral e no que toca à sua futura profissão como professores. Essa reflexão e diálogo pode nos levar a uma riqueza muito grande: situar os estudantes em suas condições, trabalhar com eles as ações curriculares necessárias, de suprimento do não aprendido e dos avanços necessários, criar motivação. Trata-se de pessoas em sua integridade, não são números, nem seres abstratos. Há que se ter sensibilidade para discutir com esses alunos, em cada elemento curricular; afinal, como que podemos dar prosseguimento a partir daquilo que eles conseguiram fazer, ou não, respeitando os limites e as dificuldades e aí reprogramar. Vamos ter que ter um trabalho de reprogramação, eu acho que de praticamente todo o curso, de todos os conhecimentos que o curso exige. Creio que vamos ter um problema maior com aqueles que estarão se formando, alunos que estariam terminando em junho/julho e a alunos que terminarão em dezembro - são situações que devem ser consideradas levando em conta os estágios necessários. O tratamento, no meu entender, de estudantes que estão adentrando na licenciatura, deverá ser muito diferente daqueles que estão nos anos finais. E, o grande problema, que vejo, não é o redimensionamento do currículo, se nós, professores, tivermos a sensibilidade de conversar com os estudantes que estarão aos nossos cuidados. Mas, acho que há um problema com os estágios, os estágios curriculares obrigatórios. Cada instituição talvez tenha que fazer uma regulamentação diferente para isso, porque quem tem que fazer o complemento do estágio agora, para se formar, merece outro planejamento e formas 
de realização. Como é que você vai fazer se ele tem que fazer muitas horas de estágio? Ainda, porque também, a programação de estágio nas diferentes instituições tem distribuição muito diferente. Há instituições que têm as 400 horas distribuídas em100 horas no primeiro, no segundo, no terceiro e no quarto ano, mas têm instituições que só fazem estágio a partir do terceiro ano e até só no último ano. Como redistribuir sem prejudicar as aprendizagens que o estágio propicia? Então, a ideia é o planejamento dos professores com sensibilidade e objetividade, considerando as situações. Acho que isso vai exigir uma coisa que dificilmente a gente encontra no ensino superior; vai exigir, antes da volta dos alunos, reuniões pedagógicas em cada licenciatura, com todo corpo docente envolvido, para estudar situações possíveis, alternativas para o retorno desses alunos. Acho que isto será uma coisa muito diferente. Já estou vendo esse momento aqui, na Universidade de São Paulo, que possui um fórum dos coordenadores de cursos de licenciatura, e eles já estão se preocupando com isso, mas acho que a reunião curso por curso de todos os envolvidos, para desenvolver primeiro aquilo que eu falei - uma sensibilidade com relação ao retorno dos alunos, com diversidades enormes com diferenças de aprendizagem e oportunidades no período.

Segundo, como reestruturar a sequência dos semestres depois da volta de tal maneirar que a gente atenda aos diferentes níveis do curso e o problema do estágio que deverá ser resolvido. Vou falar uma palavra - não me levem a mal - precisamos resolver com inteligência e com conhecimento pedagógico, ou seja, muito bem pensado - nós podemos incluir várias atividades diferenciadas, pensar em outras alternativas didáticas além da "saliva e giz (ou projetor)": projetos temáticos que mobilizem, estações de trabalho, grupos de estudo, etc. Dou exemplo daquilo que é experiência aqui, fazendo parte dos estágios, a participação deles junto às diretorias de ensino, tendo senha de entrada nas aulas on-line de professores, que estão sendo oferecidas aos alunos na rede estadual de ensino. Assistem, coparticipam com o docente, ajudam no planejamento, etc. Passam a ter domínio da tecnologia e seus aspectos pedagógicos. Então, isso vai ser considerado como estágio, desde que a diretoria de ensino, a escola e a universidade registrem essas horas. É uma maneira de introduzir os licenciandos nessas novas metodologias, num lugar onde isto ocorre. Vamos ter que pensar, em alguns casos, como condensar esses estágios, num período mais curto, porque alunos já perderam a oportunidade de iniciar seus estágios. Mas isso tem que ser feito considerando as possibilidades dos estudantes. E a questão, também, está em torno, no caso das universidades federais e particulares, em torno das orientações do Conselho Nacional de Educação. Vão fazer as orientações, pode ser que venha uma extensão do ano letivo, para janeiro e fevereiro, pode ser que não venha. Se vier ou não vier serão dois casos que o curso deve considerar, mas a minha 
opinião é que essa volta tem que ser preparada pelo coletivo de professores in loco - e muito bem preparada, porque, senão, os estudantes serão submetidos a uma fragmentação de soluções de professor a professor, que podem se chocar uma com as outras e, até, podem ser criadas condições de não cumprimento por parte dos alunos, por exigências exageradas ou por exigências descabidas, ou seja, nós vamos ter que nos ater ao essencial, o que é essencial de cada disciplina, em cada um dos cursos, o que o aluno tem realmente que aprender, e, deixar de lado aquilo que é mais acessório, complemento, porque isso ele poderá cobrir em outras formações, em outras circunstancias. Em princípio, é isso, mas, sem sensibilidade para entender os diferenciais que estarão na nossa frente, haverá muitos prejuízos. Na sala de aula presencial, no retorno, não vai adiantar se eu quiser tocar minha vida do mesmo jeito que antes.

E, há outro aspecto - a nossa forma de lecionar no ensino superior é uma forma arcaica! Nos esquecemos de metodologias ativas e interessantes e de incorporar medidas que favorecem a capacidade de compreensão dos alunos e o desenvolvimento das aprendizagens dos alunos com as atividades de sala de aula. Você tem recursos que você pode fazer uma parte presencial, na universidade, uma parte à distância, por exemplo, utilizando situações-problema, desafiando os estudantes com questões interessantes, com organização com assuntos de interesse na educação básica, com análises da BNCC. Ou seja, sermos criativos didaticamente e isso é um problema no ensino superior, porque os professores, de modo geral, especialmente das áreas específicas, muitas vezes não fizeram licenciatura e, quando fizeram, pode ter sido num estilo sempre desfavorecendo o estímulo e interesse pela educação. Mas, de qualquer maneira, estando no ensino superior como docentes, como professores, não adianta querer dizer - eu sou pesquisador e encher o peito, não! Essencialmente, você é Professor, porque o que dá vida e razão de ser da universidade é a formação das novas gerações - o educar. Então, nós teremos que até pensar nos nossos professores, nas dificuldades didáticas que têm para trabalhar com seus alunos e com quais recursos e apoios didáticos eles podem ser enriquecidos, para poder trabalhar de modo diferente com os estudantes. Então, as dinâmicas curriculares também podem ser discutidas se nós fizermos essas reuniões coletivas com o corpo docente e reuniões de compartilhamento, reuniões de troca, que podem gerar planejamentos, não só para o retorno de modo geral, mas, planejamentos pedagógicos para o trabalho disciplinar. Acho que nós temos que pensar muito nisso, eu estou vendo algumas universidades que já estão planejando para fazer trabalho integrado, entre horas presenciais e horas à distância e criar formação interdisciplinar. Acho que vamos ter que pensar todas essas condições, porque também não vamos poder encher a sala de aula de uma maneira plena, porque o vírus vai estar por aí - claro que nas cidades com maior densidade isto é mais problemático. Então parece que teremos uma 
continuidade semipresencial por um tempo, porque nós não teríamos ainda criado a resistência suficiente ao vírus para que a gente se desloque à vontade, como já nos deslocamos com relação a outros vírus. Acho que eu fico por aqui, depois a gente pode conversar um pouco mais sobre essas questões.

[SHAW, G. S.L.] Professora, obrigada! Boa tarde! Eu gostaria de agradecer muito a sua participação é um privilégio para gente ter uma oportunidade de ouvir suas opiniões, que geralmente apenas lemos sobre suas pesquisas. Estamos vivendo um momento que é de crise, em todos os aspectos, de perplexidade, e as pessoas já vêm discutindo há muito tempo o uso de novas tecnologias. Boa parte dos professores nunca se apropriou adequadamente de como trabalhar com essas tecnologias na sala de aula. Ao mesmo tempo, durante muito tempo, sempre houve muita preocupação com conteúdos conceituais, com aulas expositivas e, aí, de repente, nessa situação tão conflituosa, os professores estão tendo que lidar com muitas discussões de como utilizar a máquina, a tecnologia, softwares e tendo que discutir como a gente vai saber se o aluno tem acesso à internet. É uma coisa óbvia, a gente ter que trazer o aluno para perto da gente e perguntar para ele, mas a gente não tem visto essa coragem, de estar buscando os alunos e estar perguntando: Você tem internet em casa? Você tem computador? E é uma preocupação que a gente já deveria ter tido, há muito tempo. E, ao mesmo tempo, a gente está discutindo coisas não novas para muita gente, mas que, para nós, da pedagogia, sempre ouvimos, na formação: a importância da criatividade, a importância da autonomia. Pró, você não acha que esse é o momento que vai demarcar uma mudança de paradigma? Será que a gente não vai mudar nossa cultura da educação, tanto na universidade quanto nas escolas? Será que não é o momento de abalar as estruturas para a gente começar a pensar coisas que a pedagogia já fala há tanto tempo e que muitas vezes as pessoas não dão ouvidos? Até porque nossas universidades têm professores que nunca tiveram uma aula de didática!

[GATTI, B. A.] É isso mesmo, é uma realidade!

[SHAW, G. S.L.] O que você acha que vai acontecer em relação a isso, a essa mudança na educação?

[GATTI, B.A.] Eu acho, em primeiro lugar, que os estudantes vão voltar diferentes, eles vão voltar com outras necessidades, porque eles estão conversando entre eles, eles trocam por WhatsApp, telefone, por e-mail. Têm vivências específicas nesse isolamento social. Mas, penso 
que eles estão construindo uma nova perspectiva de como aprender e porquê, e isso, creio que vai, realmente, entrar em choque com perspectivas muito tradicionalistas das formas como no ensino superior tratamos as disciplinas. Por aí pode vir alguma mudança, acho que a universidade como um todo, em meu entender, ela tinha, também, que providenciar algum tipo de discussão com seus docentes, nessa direção: que perspectivas eles estão tendo para pensar novas dinâmicas curriculares? Quando seus alunos voltarem, que não fique só na volta, que sejam atitudes mais permanentes. Para falar a partir da experiência que a gente tem com os resultados de pesquisas junto a cursos ou professores que inovam alguma coisa, quando há uma inovação por parte de um, dois ou um grupo de professores, isso perturba os outros professores, porque os alunos questionam os outros professores, em relação ao como eles estão conduzindo a disciplina. Já assistimos a choques e também a mudanças curriculares com isso. Então, o papel da universidade, da Pró-Reitoria de Graduação, nesse momento, vai ser muito importante levar avante uma maneira de articular seus docentes e problematizar, com eles, as condições que eles têm para elaborar formas didáticas diferentes, por exemplo, algumas que aprenderam com o uso das tecnologias de comunicação, e outras. Primeiro, abordar em suas disciplinas formas diferentes de utilizar metodologias, de ações pedagógicas, cabe à Pró-Reitoria de Graduação a liderança desse processo, o estímulo para isso, e, providenciar apoios. Ao liderar esse processo, não impor formas, mas ajudar a que se pense sobre novas formas, estimulando os professores que se motivem a procurar formações diferenciadas, no sentido do pedagógico, porque quem dá aulas no ensino superior é professor, é um docente que tem sob sua responsabilidade a juventude do país, o futuro. Então, precisaria haver estímulos, cutucar um pouco esse pessoal, provocando. O papel será de provocação e de oferta de ajuda. As PróReitorias de Graduação podem oferecer um acervo de softwares educacionais, links para sites: há softwares educacionais maravilhosos, na área de matemática, na área de ciências, seja na biológica, na física, temos acervos enormes disponíveis que podem ser utilizados, não para substituir a relação professor/aluno, mas para mobilizar aulas. Bons softwares fazem com que professor e aluno se aproximem, porque o professor faz a mediação daquilo que o software pode ajudar a desenvolver como conhecimento. Acho que, nesse caso, a oferta de formações diferenciadas, para desenvolver o currículo necessário, um esforço de aperfeiçoamento, pode ser um elemento tão estimulador para o próprio professor, o qual, muitas vezes, se sente abandonado na sua sala de aula, porque chega na universidade - "Você vai dar tal disciplina em tal sala"! E, pronto! É um vire-se! Quem sabe se a gente conseguir estruturar junto à Pro Reitoria de Graduação um setor didático de ajuda aos professores? Nós temos um exemplo muito interessante na Unicamp. Um setor de apoio didático aos professores, que nasceu há uns 10 
anos. Atendem por demandas. Têm tido demandas de muitas áreas, por exemplo, do pessoal da medicina e das engenharias, porque os alunos que ingressam são jovens, 17, 18 anos, e esses professores refletiram que não estavam conseguindo se comunicar com esses jovens, com seus jargões, que tinham a percepção de que eles tinham dado uma ótima aula, mas os alunos não estavam entendendo nada. Então, alguns professores começaram a procurar o pessoal da Psicologia educacional da Faculdade de Educação da Unicamp. Primeiro, como é que o jovem aprende? Quais são as características do jovem, psicossociais e culturais, como eu falo com eles? Existem maneiras interessantes para trabalhar com eles? Isso foi gerando interlocuções e soluções e se criou o Espaço de Apoio ao Ensino e Aprendizagem na universidade, hoje muito requisitado. Um espaço onde existe possibilidade de atendimento a demandas da comunidade universitária, demandas de qualquer grupo de professores, de qualquer curso e lá eles têm um trabalho com recursos, recursos presenciais, à distância, recursos didáticos, etc. É um tipo flexível de formação para a docência no ensino superior. Nessa seara, que é essa área do profissional docente, que é a seara da responsabilidade que têm para a formação dos jovens que estão sobre seus cuidados, que, em geral faltam apoios, né? Seus cuidados, no sentido de propiciar a eles aprendizagens significativas, porque os jovens, eles irão para o mundo, eles irão para uma cidadania e para o trabalho, e nós precisamos considerá-los nos seus contextos, nas suas necessidades e nas formas novas que facilitam a comunicação com eles - é uma questão ético-social. Hoje, os jovens demandam que você trabalhe com eles, simulando situações, criando desafios, estimulando perguntas sobre os conhecimentos. A vida social está mais dinâmica e o ensino tem que ser mais dinâmico, desafiador no coletivo, com cooperação. Como um conceito desta ou daquela ciência se formou, qual sua história? Modificou-se? Há dúvidas? Margens de erro? Trata-se da construção de conceitos e suas relações, decorrências e limites tratados de forma desafiadora, não "decoradora". Não é decorar o conceito, né? Veja! Na matemática, nós temos tantos conceitos, trabalhamos com tantos teoremas, ou o que seja, mas, isso alguém pensou, algum dia, diante de um problema que o desafiou, e, não só a um, mas, a vários estudiosos. Como se chegou lá, porquê? Com quais fundamentos? Quando você coloca o conceito que foi elaborado em função de que problema, quais desafios foram enfrentados, em que circunstância, isso em qualquer disciplina, isso é uma das coisas essenciais! O estímulo é outro - "Ahhh! Alguém pensou nisto, um grupo de pessoas pensaram nisso, não caiu do céu, não é um conhecimento adivinhado! Ele é um conhecimento construído historicamente, construído por pessoas que trabalharam com determinadas problemáticas, seja na área de ciências humanas, seja na área das ciências biológicas, ou exatas”. Creio que introduzir esse tipo de questões e discussão dinamiza. Bom, é perguntar-se - será que meus alunos estão 
aprendendo algo comigo? Será que esse estudante que está na minha frente aprende? Vamos pegar engenharia, pegue Cálculo I, em curso de engenharia - É um terror! E é um terror por quê? Porque o professor chega, começa a dar aquelas coisas lá, vagas, limites e não sei o que ao infinito, demonstra ou o que seja, e blá, blá; sem olhar para os estudantes ou olhando sem ver, e os alunos ficam "boiando".- ficam boiando porque a forma como o professor apresenta é uma forma já estruturada, extremamente formalizada, é uma linguagem específica, e ele não faz esforço para introduzir o raciocínio junto aos alunos para o desafio da construção de um conhecimento fundado. Pensar nisso é o pedagógico! Então, precisamos sim trabalhar nessa direção, repensar didáticas, evitar evasões de alunos. A Pró-Reitoria de Graduação teria um grande papel aí, o de oferecer apoio ao ensino em formas dinâmicas e compartilháveis. Fazer isso, pode originar-se de discussões com vários setores, ou do trabalho de um fórum, onde dificuldades são colocadas, onde se facilitem levantamento de problemas e necessidades, onde se provoca os professores também. Eles precisam ser provocados quanto ao seu ensino, porque no nosso cotidiano são tantas as coisas que temos que fazer e ficamos assim, nas nossas particularidades e esquecemos de olhar um pouquinho além, de modo mais amplo. Esquecemos também de fazer uma autocrítica daquilo que nós estamos fazendo. Por exemplo, numa sala de aula, precisamos sair só do polo meramente discursivo da "ação-reflexão-ação" e pôr isso em AÇÃO, dialética e dialogicamente. Falta esse pulo do gato! Como é que eu vou fazer para acionar e motivar esses professores, no ensino superior, a pensar em suas práticas para os estudantes que estão vindo? Ou seja, seres humanos num contexto histórico, de uma determinada comunidade, com determinado tipo de cultura e com determinado domínio, ou não, de certos conhecimentos. Comece-se por aí! Então, temos muito o que fazer em relação, e a favor, dos nossos docentes do ensino superior, acho. Vamos abrir espaço para isso, né? Para uma boa educação. Porque isso é muito importante! Eu falo aqui, há universidades tradicionais, grandes, em que qualquer mudança é difícil - hábitos e hábitos, para se mexer é duro! No entanto, algumas estão se mexendo, porque esta pandemia mexeu com todo mundo, mexeu com as relações, mexeu com muitas das dúvidas que ficavam apagadas, ou deixadas de lado: "ah eu tenho que fazer minha pesquisa, eu tenho reunião de não sei o quê" e a aula, a relação pedagógica com seu aluno fica em segundo, terceiro ou quarto plano, quando deveria ser a primeira preocupação. A aula apareceu na pandemia, com desafios.

[PEREIRA, J. G. L. T.] Professora Bernadete, nós temos a participação nessa Live de pessoas de diferentes locais do Brasil, de várias regiões, e através da participação, com muitos questionamentos, muitas dúvidas interessantes, registro que já estamos passando de 300 pessoas 
assistindo com muitas dúvidas. Vamos, desde já, pedir desculpas, porque, pela grande quantidade de perguntas, provavelmente não iremos atender a todos os questionamentos, mas vamos escolher algumas e espero que com elas se contemple muitas. A partir desse momento, nós vamos ler algumas perguntas e discutir com a professora Bernadete. A primeira delas veio da Jaci Luz Dias, ela diz assim:

Eu tenho uma pergunta, existe o risco de que vendo que a educação a distância "funciona" o governo amplie a política de EAD para a formação básica, como já foi sinalizado? (CHAT 01 v. 0:00 segundos)

[PEREIRA, J. G. L. T.] E ela coloca em outras palavras:

Será o motivo que o governo queira para diminuir a quantidade de professores e aumentar a de tutores? (CHAT 02 v. 0:00 seg.)

[PEREIRA, J. G. L. T.] Uma pergunta muito interessante, alguns participantes que leram a pergunta dela também disseram achar uma pergunta muito pertinente na discussão. Por isso, queremos ouvir a professora Bernadete, o que acha, qual sua opinião sobre esses questionamentos?

[GATTI, B. A.] Olha, vou falar primeiro da Educação Básica, a pergunta começou com a educação básica, não é? Eu não vejo perspectiva de que a educação básica, por mais que o governo force, venha a ser transformada toda à distância, porque, primeiro, nós temos a lei de diretrizes bases que dispõe que essa educação deve ser presencial. Nós não podemos romper com isso. Abriu-se a possibilidade de que trinta por cento dos cursos do noturno, ensino médio, possam ser à distância, mediados, de acordo com determinadas exigências. Aqui em São Paulo nós só admitimos vinte por cento, porque o Conselho Nacional de Educação fala até trinta por cento, se é até trinta por cento pode ser um por cento, pode ser cinco por cento, etc. Para bom leitor, é isto. Nos limitamos a vinte por cento, mas os nossos cursos diurnos eles terão que ser presenciais. O que está mais aberto, por lei, como possibilidade a distância, é a formação profissional técnica, esse sim tem uma regulação específica para isso e, aí, para analisar isso, eu teria que ter um longo tempo para explicar um pouco como é que isso está funcionando. E só para informar rapidamente, há um acordo de regulamentação que foi consensuado entre 27 Conselhos Estaduais de Educação para garantir oferta com certa qualidade, porque instituição de um estado, com a EaD, pode ofertar no país todo. Então, não é qualquer oferta de curso técnico-profissional à distância que é aceita, ele tem que cumprir determinados requisitos e com visita de especialistas, que vão verificar as condições nos locais de ofertas, inclusive, nos polos, 
e com um credenciamento só de cinco anos (depois tem que renovar a autorização), coisa que é novidade para a educação básica. Por que para a educação básica? Porque a educação profissional média faz parte da Educação Básica. Então, essas instituições que oferecem EAD profissionalizante, que foram abertas pela legislação, elas têm credenciamento de cinco anos e, após cinco anos, têm que pedir de novo, pedido antecipado de um ano. Podem perder a autorização e seus cursos não serão válidos. Então, é um fluxo. Temos assistido à diminuição das instituições ofertantes, porque antes havia uma avalanche; quando se conseguiu esse entendimento de consenso entre os 27 Conselhos, em suas normas, segue-se aqueles critérios que são bastante exigentes. Diminuiu muito o número de instituições que vieram procurar por isso, então o papel do estado na regulação dessas coisas é muito importante. Infelizmente, nós realmente ficamos muitas vezes com legislação que não é de estado, é de um governo e seus interesses, mas nós precisamos ter atenção e consciência no que diz respeito à educação básica. Pela LDB, temos o que é de responsabilidade dos estados e o que é de responsabilidade dos municípios, e do federal. Nós precisamos conhecer um pouco a legislação, somos uma federação, não temos que abaixar a cabeça para MEC, em muitas coisas ele afeta apenas o que é da rede federal. Há certas regulações que ele faz que estados e municípios não precisam, em sua autonomia, atender, porque a educação básica é sobretudo atribuição de estados e de municípios. O que vem do Congresso, sim, é nacional. Temos que ter muita consciência disso e saber onde é que vamos colocar nossa luta. Há coisas que lutamos junto ao MEC, que não são de responsabilidade do MEC, é do estado ou do município por seus órgãos de governo secretarias de educação, ou conselhos de educação estaduais ou municipais. E a nossa Lei de Diretrizes e Bases da Educação é sábia em muitos aspectos, porque preserva, com clareza, as responsabilidades distribuídas entre o nível federal, o estadual e o municipal. Preserva a diversidade desse país e considera as diferenças. $\mathrm{O}$ que pode ser importante para uma região, como regulação, pode não ser para outra. Temos que ter essa consciência, de sair daquilo que eu chamo de "pensamento unitário" (que tem muito de totalitário). Porque, se nós queremos considerar diversidades e as diferenças, e não queremos ter diferenças aviltantes, temos que pensar muito naquilo que é local, regional, porque é ali que estão as necessidades e as tomadas de decisão que ajudam esse local, esse regional, com suas características e carências em relação à educação. Agora, a educação superior, está sob a regência do Conselho Nacional de Educação (CNE) e do MEC, no que diz respeito às instituições federais e particulares; as universidades estaduais estão sob a regência de seus Conselhos Estaduais de Educação. Só no que diz respeito a currículo é que o CNE tem prevalência nacional. Então, nós, aqui em São Paulo, temos uma rede estadual grande de ensino superior, que tem regulação própria. Em outros estados, como 
Ceará e Bahia também isso ocorre. Claro que há entendimentos, trocas com o nacional. Agora, as diretrizes curriculares dos cursos que emanam do CNE têm que ser atendidas por todos os estados, os quais podem complementar currículo, porém, o básico quem determina é o CNE. Esta consciência de como o Estado Brasileiro se estrutura e como nós podemos lidar com as diferenças, é uma aprendizagem que nós temos que ter, né? Porque nós estamos muito acostumados a ficar pendurados em questões com o governo central e esquecemos que os estados têm, sim, um poder definido pela constituição, assim como os municípios, e, no caso da educação, um poder muito grande, definido pela Lei de Diretrizes e Bases da Educação Nacional. Temos que saber quais são os órgãos reguladores sim, porque nossa luta tem que se concentrar onde pode haver soluções, conseguir efeitos onde é possível, conseguir modificações e conseguir diálogos, com debate de pontos de vista - tomara que com muito debate! Porque, sem debater, cabeça única, pensamento único - gente, isso não é, bom para ninguém, não é bom para a educação básica, não é bom para a educação superior, muito menos a divergência pela divergência ou por interesses particulares deste ou daquele grupo. O bom senso e o bem comum têm que estar presentes nas questões que afetam a educação da população brasileira, do povo. Então, a questão da oferta de cursos na modalidade EaD no ensino superior, pela legislação, é afeta ao $\mathrm{CNE}$, ao MEC e às regulações estaduais onde couber, pelas normas. Há uma boa normatização para o ensino superior em $\mathrm{EaD}$, a questão está na concretização delas pelas instituições. Não há acompanhamento e monitoramento adequado por parte dos órgãos responsáveis. Os processos de avaliação existentes não são funcionais, nós teríamos que ter uma avaliação qualitativa, de processos e condições de oferta com olhos nas práticas educativas, se adequadas ao público que frequenta esses cursos. Pesquisas com os estudantes sobre o cumprimento de requisitos para estudos em $\mathrm{EaD}$, por exemplo, seriam bem-vindas. Com que formação terminam seu curso, que cultura cidadã formaram, que cultura geral adquiriram, que condições adquiriram para a profissão escolhida? E os estágios, seu acompanhamento (aliás questões que podem ser colocadas para os cursos presenciais também). Laços sociais e redes são criadas e mantidas visando socializações? A preocupação colocada é válida, porque há gestão e gestores que pensam mais no custo do que nas pessoas. Gente, é muito válido pensar "vai transformar tudo à distância? " Não acredito, pelo que estou observando e, segundo pesquisas, tanto com professores, como com estudantes, de todas as partes deste país, que mostram a necessidade que todos sentem da presença e as limitações que o vídeo, mesmo "ao vivo", impõe para os diálogos coletivos e a emergência de dúvidas e problemas, como acontece "à quente" nas aulas presenciais. E, também, se aponta a dificuldade de observação de gestos e olhares pelos quais professores detectam facilidades e dificuldades com os conteúdos. De um 
lado, a experiência com o ensino remoto é considerada relevante e interessante, mas, também, de outro, estão alunos e professores estão mostrando as dificuldades de aprendizado na forma remota, para não falar das dificuldades com a máquina, a internet, os softwares. Estão apresentando grandes dificuldades de aprendizagem em áreas científicas onde conceitos abstratos são muito importantes. Pensem bem, um aluno saindo do ensino médio, vamos dizer que vai fazer pedagogia e ele tem que enfrentar uma disciplina de sociologia que tem um jargão próprio, textos complexos e, podemos falar de outros, história da educação, psicologia cognitiva e da aprendizagem, ele vai ter que dominar linguagens diferentes, e essas linguagens diferentes trazem suas dificuldades. Ou, se pode cair em simplificações, empobrecimento de textos, e os estudantes sentem que não estão avançando culturalmente, se ressentem disso. Os estudantes estão problematizando essa questão de aprender só por um instrumento, seja o seu computador, seja o seu celular, e de muito tempo diante de tela gerando estafa. É cansativo, é muito cansativo, né? Em uma sala de aula presencial a conversa corre fácil, há interrupções rápidas. Espera aí, professor: o que que está se passando, como é, eu não estou entendendo aqui! $\mathrm{Na}$ situação remota, em grupo, difícil essa chance rápida, por mais que falem que há interatividade, essa interatividade tem um tempo para se efetivar quando se trata de um professor e muitos alunos, ao mesmo tempo, e às vezes se perde a motivação da pergunta. Voltando com a dificuldade de leitura de textos complexos, que acompanham muitas vezes essas aulas virtuais, textos que podem ser discutidos numa aula presencial, e que professores declaram que levam, às vezes, três aulas virtuais para seu deslindamento com os alunos. Eu tenho visto aqui textos do pessoal, seja da USP, seja da PUC, que um assunto que ele dava em três horas-aula, estão levando o dobro ou o triplo do tempo na aula on line. Então, há dificuldade de destrinchar os textos à distância, sejam eles da área de ciências biológicas, sejam eles da área de matemática. Tenho visto as aulas de universidade de Cálculo e fico assustada - Quem é que vai entender essa aula de Cálculo, sem alguém, destrinchando melhor aquilo? A aula é dada escrevendo numa lousa, falando com a lousa, demonstrando, símbolo atrás de símbolo, o quê que é isso, né? O aluno nunca viu, ou viu pouco daquela simbologia na frente dele, ele tem que ser introduzido aos poucos, de modo a construir seu pensamento com desafios. Então, assim, as formações à distância têm mostrado muitos problemas. Isso tem aparecido, eu não sei se vocês têm visto, mas nós temos recebido, especialmente no Conselho Estadual de Educação, nós recebemos de pais de alunos da Educação Básica, muitas queixas que as escolas estão entupindo seus filhos de tarefas e com horas a fio de vídeo, acima daquilo que era o presencial, inclusive, e que os filhos não estão aguentando. Então, não estão aguentando de cansaço, de cansaço, então, uma aula virtual, ela requer o dobro de atenção, de fixação, do que uma aula presencial; não é como 
assistir a um filme. Na aula presencial se está de corpo presente, tem coleguinhas, você dá uma risadinha, o outro dá uma risadinha e a coisa flui, né? Há um emocional ali que ajuda o cognitivo - fala com o colega, o professor pergunta o que há, etc. No virtual, você não sente que você está junto, não pode tocar, trocar palavras baixinho, você "estar com", é diferente de só "se ver com". Eu acho que vai ser muito difícil, isso, de se converter o ensino à distância totalmente. É um recurso para certas situações. Generalizar o ensino em modalidade à distância não será tranquilo. $\mathrm{O}$ que está em pauta são duas questões - o ensino híbrido, alternando presencial e remoto (o que não quer dizer sem professor, ao contrário) e o uso como recurso didático nas aulas presenciais ou como recurso complementar. O papel da educação escolar, no que se refere à formação social dos estudantes, é fundamental - ali aprendem a compartilhar, viver a vida pública, coletiva. Os recursos à distância podem ser usados muito bem para tutoria, revisões, podem ser usados como estímulo, através de emprego de vídeos e contatos e discussões eventuais, extracurriculares ou com participação de especialistas, etc., mas não para substituir a aula do professor. Agora, a aula do professor também precisa ser olhada, vamos e venhamos, gente! Nós já levantamos esse problema - professor de ensino superior nem sempre sabe dar aula, né? Vamos falar o que é verdade, alguns também criam dificuldades. Mas, de qualquer maneira, ele está ali e as perguntas, "à frente" do estudante, são muito importantes nesse contato ativo, embora haja docentes que não permitam interrupções.

Agora vou falar de dados - nos dados, que a gente coletou para nossa última pesquisa, que estão mostrando o seguinte: o pessoal vai para educação à distância, estou falando das licenciaturas, ele vai para educação a distância, mas muitos não ficam na educação à distância; faz um dois módulos, sai da educação à distância e está procurando a presencial, está voltando ao presencial, justamente por essas dificuldades que eu acabei de falar, dessas questões que não satisfazem ao aluno - dificuldade de leitura, etc., por mais rico que seja o programa feito à distância. Há programas muito bem elaborados, mas têm todos esses efeitos colaterais que precisam ser considerados. Então, o que nós vemos - o número de pessoal matriculado à distância sofre uma quebra, com transferências para o presencial. Então, essa passagem da volta a procurar o presencial é sinalizadora de alguma coisa. São pessoas de mais idade, em geral, de mais de trinta anos, que permanecem nos cursos à distância. Justamente, porque eles já estão em uma outra fase no mundo do trabalho e eles vão fazendo os módulos à medida que podem. Mesmo assim, a evasão é grande. Pode ser que nossa previsão esteja errada, mas acho que fatos estão mostrando que os próprios estudantes não aguentam o tempo todo trabalhar à distância e os professores também. Há relatos, de professores, que nós estamos coletando, da exaustão que é você preparar as suas aulas e, não é só isso, você está com seus alunos aquele tempo e 
percebendo que a interlocução se torna um tanto quanto complicada e que certas dúvidas, que ele perceberia olhando para sala de aula, para todos, os sinais corporais de olhar de reticente, de permitir falar - Não, eles não tão entendendo; ah, estão entendendo; bem, eles não têm mais esse sinalizador, vamos dizer, que é mais presencial. Então, há muitos professores - e nós já estamos no clamor aqui, no estado de São Paulo, dos professores estaduais - que eles estão se considerando, vamos dizer, esfolados por ter que ficar horas e horas e horas preparando aulas, refazendo, tentando conversar com seus alunos, depois fazendo tutoria. É cansativo para os dois lados! Então, vamos esperar e por mais que o governo queira pôr tudo à distância, eu acho que não vai ser possível, na Educação Básica, com certeza, porque aí as nossas associações entram no supremo tribunal e derrubam qualquer coisa disso, porque a LDB não permite, tem que ser presencial. E, no superior, porque os jovens, eles vão procurar o presencial sempre que puderem. Ir à faculdade tem outro sentido humano além do cognitivo - tem o social, ter laços efetivos. Mas, o pessoal fala assim: Ah, mas está diminuindo a procura dos cursos! Bom, aconteceram duas coisas, olhando grandes bases de dados - o que é que está acontecendo? Primeiro, aumentou a oferta de cursos superiores absurdamente, absurdamente! Nós temos, às vezes, três milhões de vagas sendo oferecidas para procura de oitocentos mil alunos. Segundo, diminuíram os nascimentos. Há trinta anos nós estamos verificando que, no país, a curva de crescimento da população por nascimentos está com uma tendência de chegar a uma plataforma, ou seja, quando a gente tinha cinco, seis filhos, sete filhos, agora o pessoal está tendo um, dois. Quando tem três, falam: Nossa, você tem três filhos! E isso já está batendo no ensino médio e está batendo no ensino superior. Nós estamos com faculdades particulares que estão quase sem alunos, porque, realmente, não tem gente para tanta oferta. Alguns cursos de [universidades] públicas também têm tido esse problema (grifo nosso). Duas coisas: questão demográfica e questão de seletividade socio educacional - abandono escolar, para chegar ao ensino superior. E, agora, eu vou falar de um fator perverso: a trajetória de crianças e jovens na educação básica. Vinte por cento de nossas crianças não terminam o ensino fundamental e, das que terminam, nem todas vão para ensino médio. Dessas, terminam o ensino médio só cinquenta por cento. Então, não há possibilidade desse jovem se candidatar ao ensino superior, e a EJA não tem dado bons resultados para corrigir isso, são poucos alunos que realmente terminam a EJA e, também, podem se candidatar pela EJA ao ensino superior. Isso é perverso, isso é a seletividade social que nós estamos propiciando através da educação básica! Onde, ao invés de nós acolhermos os alunos numa progressão continuada de aprendizagem, pelo coletivo dos professores, nós estamos expulsando esses alunos da sala de aula. Isso é difícil, isso é duro e nós temos uma avaliação disso, nós temos avaliações regionais, que nós poderíamos considerar muito para 
ações educacionais. O que está acontecendo com a trajetória dos alunos da educação básica, por exemplo, no Nordeste, que é onde nós encontramos a maioria dos problemas, o que está acontecendo na região norte, que é o segundo lugar, o que está acontecendo na região centrooeste, assim, por diante, na [região] sudeste, porque que tem abandono, porque que têm os alunos que não vão adiante (grifo nosso). Essa preocupação nós vamos precisar ter, porque, o que nós estamos fazendo com nossas crianças e adolescentes, em sua trajetória escolar, em parte? Nós temos algo a ver com isso! Nós formamos professores, nós formamos gestores, e eles ao trabalho vão com essa cabeça da cultura que lhes foi passada. A cultura da aprendizagem, ela tem que ser passada, não a cultura da reprovação e da exigência absurda. Quando a gente discute, por exemplo, com professores da educação básica em como pensar a avaliação, há uma discussão que a gente sempre faz: Você acha que todo mundo se interessa por história? Você acha que todos os seus alunos se interessam por matemática? Você acha que todos os seus alunos se interessam por ciências biológicas ou por arte? Todos têm que tirar dez em tudo? Claro que não! Eles têm gosto, preferências, mas têm direito à cultura. $\mathrm{O}$ aluno que vai chegando com seus dez anos, ele já vai começar a ter uma coisa, que Kant chamava de gosto, nós chamamos de motivação, de escolha por uma forma de pensar, porque ele está estruturando seu pensamento, ele já começa a ter mais facilidade pelo gosto em algumas coisas: Nossa, matemática! Nossa, tem aluno que adora matemática! Não quer nem ver história! Então, como é que eu vou exigir que todos os meus alunos sejam excelentes em todas as disciplinas? Desculpem, me distanciei.

[SHAW, G. S.L.] Tenho até uma pergunta que casa com esse seu comentário, que é:

Professora Bernardete será que esse momento vai nos proporcionar o repensar efetivo da formação de professores, para além da disciplinarização? (CHAT 03 v. 0:00 seg.)

[GATTI, B. A.] Nós precisamos repensar tudo isso e esse é um ponto muito grave, eu penso que será necessário repensar a formação inicial deles, nas universidades, no ensino superior, e será necessário repensar a formação continuada, ao mesmo tempo, porque nós estamos adentrando, eu acredito, em um novo momento cultural. Então, nós vamos ter que pensar, não basta mais dar para o professor vagas ideias ou ideias genéricas, não é? Nós temos que dar substância ao professor. A formação inicial precisaria oferecer o que é essencial a um professor, tem que dar cultura geral para esse professor e cultura especializada na disciplina em que ele vai trabalhar, tem que dar a visão interdisciplinar, de que nenhum conhecimento é isolado, e tem que associar 
isso com a cultura escolar e o necessário ao trabalho de um docente com crianças e jovens. Não tem conhecimento, hoje, da biologia que não dependa em alguma medida seja da matemática, da física e da química, para não falar de outras áreas, cibernética, por exemplo, e lógicas diferentes. Não existe conhecimento educacional que não seja interdisciplinar, porque ele envolve historicidade, ele envolve questões sociológicas, ele envolve questões metodológicas, envolve questões de psicologia do desenvolvimento, tudo isso para gerar uma filosofia educacional e uma didática. Nós temos um conhecimento que, na verdade, na origem, ele é interdisciplinar, nós é que o fragmentamos. Então nós vamos ter que pensar como é que vamos trabalhar conteúdos específicos mais articulados no currículo, com outros conteúdos, pôr nossa formação à disposição de rachar essa fragmentação, e perceber que sua área específica está correlacionada com muitas outras, e que nós podemos fazer um trabalho bem mais integrado, sem perder, também, a especificidade -esse que é o jogo interessante, né? Por outro lado, não se pode oferecer tudo na formação inicial, é preciso escolher e escalonar. Nós temos visto algumas experiências isoladas, aqui e ali, de alguns professores. Conheço uma lá da USP do campus de São Carlos, na área das ciências biológicas, que traz uma iniciativa de ação pedagógica integrada e integrada e interdisciplinar. Há uma experiência da Universidade Federal do Sul da Bahia e, aí, toda a universidade é feita de um modo totalmente diferente e integrado, por ciclos e focos, que o aluno vai percorrendo, integrado com a comunidade, com o que eles chamam de estações de estudo - é muito interessante! Há a proposta do Complexo de Formação de Professores da UFRJ, integrando várias universidades e secretarias de educação. Então, há buscas por mudança, no reconhecimento que nós temos que superar essa acomodação, da grade curricular, das pílulas disciplinares, é uma coisa que nós vamos ter que repensar, e muito, muito. Mas, atuar integradamente dá trabalho!

[PEREIRA, J.G.L.T.] É verdade, professora Bernardete! Inclusive, dois participantes fizeram perguntas bem próximas do que a professora está colocando agora. Uma diz assim:

O momento coloca em evidência a fragilidade da formação do docente no que se refere ao rompimento com concepções e práticas tradicionalistas? (CHAT 04 v. 0:00 seg.)

[PEREIRA, J.G.L.T.] Ela faz, na verdade, uma pergunta e não uma afirmação, e depois diz: 
[PEREIRA, J.G.L.T.] E uma outra pergunta, que depois a gente vai mostrar para vocês, fala justamente isso,

Será que esse momento, é o momento de pensar em outras formas de ensinar que não aquela de em formato de disciplinas? Será que é um momento propício para pensarmos, lançarmos o nosso olhar para outras perspectivas? (CHAT 06 v. 0:00 seg.)

[PEREIRA, J.G.L.T.] Nós vamos localizar depois, nós vamos jogar essa pergunta, mas tem tudo a ver com o que a professora está discutindo nesse momento.

[GATTI, B. A.] Então, é interessante isso, mas isso tem a ver que não existe reunião pedagógica no ensino superior, nós fazemos análises criticando a educação básica. Tem umas reuniões pedagógicas do pessoal da educação básica que são malfeitas, mas nós não fazemos nenhuma, vocês entendem? Pior ainda né? Reunir os professores como eu comecei falando, discutir. Eu vejo o seguinte, nós não vamos poder perder a disciplinaridade, mas como é que da disciplinaridade nós podemos partir para a interdisciplinaridade e para a transdisciplinaridade? Como mudar nossos hábitos didáticos, preparar aulas instigantes? Nós usamos, em nossos currículos, muito pouco as oficinas com temas que interligam vários conhecimentos, nós usamos muito pouco projetos integrados, laboratórios de ensino, por exemplo, laboratórios de leituras para confrontos de pensamentos. Há tantas maneiras de você dinamizar as aprendizagens, interligar. Então, quando eu falo assim da estrutura, da grade curricular é que está lá, duas horas de história da educação, duas horas de não sei o quê, tem lá duas horas de anatomia, mas não existe nenhum momento - não é para tirar a anatomia, mas, é para dar um momento em que a anatomia conversa com a fisiologia, conversa com a química, com a física, e outras. Ou seja, nós precisaríamos pensar o currículo de modo diferente, sair da hora-aula, combinando a especificidade de conhecimentos com momentos de integração em que um grupo de professores trabalhe junto em torno de um tema-problema. Ou seja, nós temos que superar nossa visão fragmentária e nossas comodidades e pensar um bom ensino. Sair da ideia de que o estudante é que se vire. Se olharmos as grandes universidades no mundo veremos como mudaram! Pensar nas novas gerações é crucial para qualquer país, sair do eu. Infelizmente, também, o que que aconteceu entre nós, com a departamentalização, que deveria integrar, separou, contribuindo para as rupturas nos currículos dos cursos. Quem é dono do quê? Nós não conseguimos caminhar, porque nós ficamos discutindo o currículo muito teoricamente, de modo muito abstrato. É importante? É, discutir teorias de currículo, de como fundamentar os currículos, mas nós não discutimos como estruturamos, na realidade, o currículo. Falta isso, 
acho que até, por isso, que o pessoal de áreas específicas nas licenciaturas quando vão para a área da educação para fazer sua formação educacional, não gosta ou acha desnecessário, supérfluo. Como é que eu me torno ativo numa área profissional, no caso o ser professor? Então, no ensino superior, temos sido muito pouco criativos, porque trabalhamos mais abstrata e genericamente as questões curriculares e didáticas. Também, contribui para o pouco espírito coletivo, nossa carreira, que é muito individualizada, assentada na pesquisa, apenas - é competitiva; não se estimula, na verdade, a colaboração e não se dá, nas políticas internas das universidades, valor para o ensino. Eu dei o exemplo do centro de apoio aos professores da Unicamp, a reitoria fez uma convenção dos docentes a partir disso e em sua atuação colocou a melhor qualificação das graduações como meta prioritária. A melhor formação dos jovens como a primeira meta da universidade e não a pesquisa - a pesquisa vem, mas ela vem na caixa em que ela cabe bem, no uso distributivo do tempo integral. A universidade precisa lembrar que ela é essencialmente uma instituição educacional. A vida universitária é difícil para quem se dedica, [há] várias funções e demandas (grifo nosso). Temos que fazer pesquisa sim, ela é importante, muito importante, mas não é mais importante do que a função da universidade de formar as pessoas para a vida social. Acho que é por aí, eu já falei assim, demais, voltei né? Não sei se eu respondi as questões que estão colocadas, essas angústias que estão aparecendo: Será que vai ser tudo EaD? O governo vai forçar? As IES privadas vão forçar? Se sim, vamos brigar, no melhor sentido da palavra, usando nossos recursos. Eu acho que esse espírito da boa briga, não é só ser contra, ficar parado e ser contra. É fazer o movimento de novas composições, de diálogos, trocas, bons argumentos, apoiar-se em um coletivo. Quando a gente vai fazer uma luta, contra uma determinada medida, tenho que ter uma proposta para substituir aquela medida, ou até várias. A universidade não é o lugar da criatividade? As nossas lutas também têm sido sem proposta, é só negação, só negação não leva a grandes coisas, nega, nega. Não, eu estou dizendo que isso aqui não é possível, nós não queremos, nós temos esta proposta, ou esta outra, a gente pode ter duas ou três alternativas para poder debater, discutir, sei lá, levar nas assembleias, pegar os deputados da comissão de educação, levarmos para vereadores, se for no âmbito municipal. Temos que fazer nossas lutas apresentando alternativas, mobilizando todos, atingindo gestores, o que será muito importante daqui para frente - ser mais proativos, muito mais proativos. Vou pegar o momento atual, se vocês me permitem, quando começou esta questão aí da Covid-19, que o pessoal da saúde começou a perceber que a coisa era dramática, porque é um vírus desconhecido, com um percurso desconhecido no corpo humano. Agora, já está se chegando a alguns conhecimentos. Ele causava gravidades nunca vistas, um vírus que deveria provocar apenas uma gripe, em algumas pessoas provocava sintomas leves, mas, em 
muitas pessoas, leva à morte - é uma situação de perplexidade e os governos começaram a querer discutir o que fazer. Na área da educação, nós sentimos o quê, gente? Um ministério da educação totalmente ausente, totalmente, como se não existisse a pandemia, como se não existisse a reflexão nesse país, como se já não existissem mortes, como se isso não fosse demandar um isolamento e uma forma nova de nós estarmos, socialmente, pelo menos, por um bom período e estamos aí com essa situação, né? O ministério da educação não coordenou, não articulou, não dialogou, não buscou secretários de educação para conversar e programar. Cada local precisou tomar suas decisões. Desencontros. Quando foi e chegou abril, viu-se que não se encontrava diálogo com o ministério da educação, o Conselho de Secretários Estaduais (Consed), com secretários da educação de diferentes partidos, puseram de lado isso e começaram a se reunir virtualmente e a tomar decisões conjuntas, num coletivo, respeitando as diferenças de cada estado em relação ao andamento da pandemia, mas, conversando que medidas que poderiam ser tomadas em casos assim, casos assados, casos de outro tipo. Foi o Consed, e ao seu lado a Undime (União dos Secretários Municipais de Educação) que assumiram o protagonismo e isto é uma maravilha, porque sinaliza que nós somos uma federação e que nós podemos ter entendimentos coletivos ampliados para levar avante políticas educacionais comuns e não depender de um iluminado que pode ser pouco iluminado.

A Undime, através de suas regionais, começou a tomar medidas interessantíssimas e começou a fazer reuniões junto com o Consed. Nós, por exemplo, aqui no estado de São Paulo, tivemos uma interlocução grande com a Undime, nunca tivemos tanta integração da regional da Undime atuando com a Secretaria de Estado da Educação e o CEE. Claro, virtualmente, para soluções comuns, né? Então, nós temos, hoje, orientações para esse período que valem para estado e municípios, com esta cooperação. Isto é republicano, gente e isto é democracia! Ou seja, nós vemos os nossos entes representativos tomando atitudes, assumindo a frente, acho que isso foi um fato muito interessante. Então, nesse pandemônio todo, dessa situação dramática que nós estamos vivendo, apareceu um novo protagonismo e essa possibilidade do consenso entre os estados. E os governadores começaram, também, a conversar. Ou seja, vocês viram que nossos governadores se opuseram a muitas das políticas que queriam ser postas pelo governo federal? Eles assumiram o poder regional que eles têm e assumiram com a força de outros governadores, dizendo: Eu apoio você, eu te apoio. A reunião de hoje, dos 27 governadores, foi emblemática, porque eles instauraram uma nova forma de falar, ou seja, fale conosco, mas fale com iguais, porque, do ponto de vista da execução, no caso da educação básica, são os estados e municípios que atuam e respondem. Então, nós estamos mudando também nossa concepção da federação, acho que finalmente nós vamos assumir que somos uma federação e não um governo unitário, 
que depende tudo de um "deus" que resolva fazer isso, ou fazer aquilo, nós podemos ter soluções locais e regionais muito boas. Aqui, no estado de São Paulo, nós temos diferenciais grandes, por exemplo, medidas que são tomadas aqui, pela prefeitura de São Paulo, elas são tomadas em algumas cidades, também, mas não em todas. Jundiaí achou outras soluções, porque é próprio daquela região. Ribeirão Preto achou outras soluções e está com uma contaminação muito baixa, ou seja, você tem que reconhecer que há necessidade de um empoderamento local, um empoderamento local e que nós podemos ser melhores quando nós temos o nosso coletivo fazendo interlocuções em busca de soluções. Esse momento, então, pelo menos, teve isso, e acho que os cidadãos também estão percebendo isso. Por exemplo, quando as famílias estão recebendo, aqui, a cesta básica do seu filho, aluninho, que a prefeitura está mandando, nós temos visto nos chats e nas mídias como eles estão descobrindo que não é o governo federal que está mandando para eles, que não é o governo estadual, que é o governo municipal, sem propaganda. Vai só dizendo: Oh, se o aluno está matriculado em tal escola, está aqui a cesta dele com frutas, com aveia, com tudo certo. Então, o estado está fazendo uma outra coisa, que é com o ensino médio, aí foi oferecido um voucher, porque os alunos faziam lanche na escola, então, você dá um voucher e só pode comprar alimento, não pode gastar em cerveja. Então, foi se encontrando soluções e vão descobrindo - não é esta ou aquela pessoa no cargo é um conjunto, é o governo do estado e a secretaria estadual de educação! E acabou que, no momento, tem lá duas pessoinhas - é uma pessoinha passageira, que estão aí por um tempo, é passageiro. Que é outra coisa, que a gente tem que lembrar que numa democracia eles estão aí por um tempo, não é para endeusar, nós temos que sair dessa cultura messiânica que nós temos e que veio sendo cultivada desde a colônia - o imperador, o presidente. Vamos sair dessa cultura messiânica e vamos reconhecer que, localmente, nós temos possibilidades de muitas soluções que têm muita inteligência local, e é isso.

[PEREIRA, J.G.L.T.] Professora, estamos finalizando. Infelizmente, nosso horário agora estamos há uma hora e dezessete minutos (1h e $17 \mathrm{~min})$ e ainda temos muitas perguntas interessantes e a gente já aproveita para registrar nosso agradecimento a todos que estão participando, mandando seus comentários, suas dúvidas. Uma pena que não temos tempo para discutir tudo isso! Porque recebemos uma infinidade de questões muito pertinentes, dentro dessa complexidade, que é a educação. Tem ainda uma pergunta da professora Gisele e depois suas considerações finais. Após a professora Bernadete, também pode finalizar a sua fala. Gisele, por gentileza. 
[SHAW, G. S.L.] Professora, você trouxe reflexões importantíssimas para gente e eu tenho visto, nas universidades, uma discussão enorme de como ajudar os alunos. Agora, não sabemos se todos têm internet, não sabemos se todos conseguem acessar algo, mas, ao mesmo tempo, eles estão pedindo que a gente faça algo por eles, que estão ansiosos. Em sua opinião, o que a gente deve fazer nesse momento? Como é que a gente deve proceder para estar ajudando esses estudantes?

[GATTI, B. A.] Só explicando: a primeira coisa que deveria fazer é pegar a lista de alunos e tentar localizar onde eles moram, onde é que mora esse aluno e aí mandar uma correspondência para ele, de alguma maneira, se ele tem celular, se ele tem e-mail, porque deve ter algum registro na matrícula desse aluno que indique alguma coisa - a partir disso, ver o que é possível fazer com eles. Então, aquele que não dispõe nem de internet, nem de celular, ou tem internet, mas não tem banda larga, não poderá receber determinados vídeos ou algumas informações, tentar bolar alguma coisa para ficar conectado. Vou dar um exemplo da prefeitura aqui de São Paulo, não estou falando que é maravilha, mas quando eles verificaram, veja bem, nós temos nichos muito pobres aqui em São Paulo, grande parte da zona sul, boa parte da zona leste e da zona norte, o quê que eles fizeram - eles mandaram, por carretos, não é por correio, todo material feito, impresso, para a casa do aluno e, aí, com uma cartinha aos pais dizendo que se eles tivessem internet para acessar um determinado local para conversar com o diretor ou professor, que iria orientá-los na possibilidade de o filho dele ter algumas aulas remotas. Para os pais de crianças da educação infantil foi enviado um livretinho, primeiro, com um conjunto de coisas, assim - como cuidar de seu filho nesse momento, bem breve, nada de filosofia, direto, prático objetivo e, em seguida, brincadeiras que eles podem fazer com suas crianças nesses tempos e eles enviaram o primeiro livreto e agora estão elaborando outros. Tem um que se diferencia para crianças de zero a três, é um conjunto de atividades que os pais podem fazer com a criança se eles estiverem em casa, e outro de quatro a cinco anos. Nesse, as atividades são um pouquinho mais sofisticadas. Isso está tendo um efeito maravilhoso, os pais estão encantados! Vão também, assim, por exemplo, receitinhas que ele pode fazer com a criança, põe sua criança para fazer massinha de pizza, põe sua criança para fazer bolinho, põe sua criança para fazer bolachinha e vai uma receita assim, simples, farinha, açúcar e ovo: pronto! Sai uma bolachinha deliciosa! Mas, faça a criança ajudar, mexer com a massinha. Nós temos recebido fotografias de crianças na cozinha, lavando as coisas, sabe, porque a criança precisa desse movimento, precisa aprender a participar a estar ajudando e estar aprendendo muita coisa. Então, acho que nós temos que achar essas soluções, mas o primeiro passo, Gisele, é tentar ver como nós 
podemos continuar conversando com esses alunos. Então, tem que saber onde eles estão e que recursos têm. No ensino superior isso pode ser feito por curso, não precisa ser feito, assim, na universidade toda, mas pode ser a partir de cada curso, que facilita. Porque um curso pode ter trezentos alunos e a universidade dez mil, o curso pode ter 80 alunos, então ver como isso pode ser feito por mídias simples e então estabelecer esse vínculo, ou manda entregar questionário e materiais por motoboy, vai o motoboy com as coisas, tem que encontrar essas alternativas e não deixar esse estudante solto, no espaço. Gente, precisamos de muito tempo para sentar, planejar e fazer, mas, enfim, vocês são muito bons, gente, vocês estão procurando, estão procurando fazer essas lives com várias pessoas, estão procurando. Então, sentem para procurar soluções que vocês vão achar localmente, que é melhor, mas, o motoboy levar coisa para casa dos alunos é muito bom, é isso. Eu queria agradecer a todos, primeiro.

[SHAW, G. S.L.] Muito obrigada!

[GATTI, B. A.] Me honrou demais honestamente e estar aqui conversando com vocês, eu respondo totalmente, inclusive crítica, tudo bem, eu acho que cada um tem uma cabeça, ou até provocando vocês e vocês me provocando, porque eu estava lendo umas perguntas e aí: Meu Deus, preciso pensar nisso, preciso refletir melhor, preciso conversar e conversar, já vou pensando, nem sei o que vou conversar, porque, sem interlocução, nossa aprendizagem é muito limitada! Muito obrigada, e boa noite para todos.

[PEREIRA, J.G.L.T.] Professora Bernadete, muito obrigada por sua presença! Obrigada, professora Gisele! Obrigada ao Davi, excelente tradução! Você enriqueceu muito nossa live, e obrigada a todos que participaram! Novamente agradeço o apoio da TV Caatinga, foi essencial para a construção dessa live e também agradeço à Sead. Um abraço, boa noite a todos e bom descanso!

[GATTI, B. A.] Boa noite! Tchau!

[SHAW, G. S.L.] Boa noite! Tchau! 


\section{REFERÊNCIAS}

BRASIL, Ministério da saúde. Sobre a doença. Disponível em https://coronavirus.saude.gov.br/sobre-a-doenca, acesso 18/11/2020.

\section{SOBRE A ENTREVISTADA E AS ENTREVISTADORAS:}

\section{Bernardete Angelina Gatti}

Pós-doutorado, Universidade de Montreal - Canadá e Universidade da Pensilvânia - EUA; Doutorado em Psicologia, Universidade de Paris - Denis Diderot - França; Fundação Carlos Chagas (FCC), Conselho Consultivo da Cátedra de Educação Básica do IEA/USP, Conselho Estadual de Educação de São Paulo - Brasil. Correio eletrônico: gattibe@gmail.com

(iD https://orcid.org/0000-0002-9297-726X

\section{Gisele Soares Lemos Shaw}

Doutorado em Educação em Ciências: química da vida e saúde, Universidade Federal do Rio Grande do Sul (UFRGS) - Brasil; Universidade Federal do Vale do São Francisco (UNIVASF), Programa de Pós-Graduação em Dinâmicas de Desenvolvimento do Semiárido (PPGDiDes), Núcleo de Pesquisa Educação em Ciências (NPEC) - Brasil. Correio eletrônico: gisele.shaw@univasf.edu.br

\section{iD https://orcid.org/0000-0001-5926-2679}

\section{Jocilene Gordiano Lima Tomaz Pereira}

Pós-Doutorado em Ciências da Educação, Universidade de Coimbra (UC) - Portugal, Doutorado em Educação, Universidade Federal do Paraná (UFPR) - Brasil; Universidade Federal do Vale do São Francisco (UNIVASF), Programa de Pós-Graduação em Dinâmicas de Desenvolvimento do Semiárido (PPGDiDes), Núcleo de Pesquisa Educação em Ciências (NPEC) - Brasil.Correio eletrônico: jocilene.pereira@ univasf.com.br

(iD https://orcid.org/0000-0002-5036-0990 